\title{
ABO and Rhesus Blood Groups in Acute Puumala Hantavirus Infection
}

\author{
Johanna Tietäväinen ${ }^{1,2, *} \mathbb{C}$, Outi Laine ${ }^{1,2}$, Satu Mäkelä ${ }^{1,2}$, Heini Huhtala ${ }^{3}$, Ilkka Pörsti ${ }^{1,2} \mathbb{D}$, Antti Vaheri ${ }^{4}$ \\ and Jukka Mustonen 1,2 \\ 1 Faculty of Medicine and Health Technology, Tampere University, 33520 Tampere, Finland; \\ outi.laine@pshp.fi (O.L.); satu.m.makela@pshp.fi (S.M.); ilkka.porsti@tuni.fi (I.P.); \\ jukka.mustonen@tuni.fi (J.M.) \\ 2 Department of Internal Medicine, Tampere University Hospital, 33520 Tampere, Finland \\ 3 Faculty of Social Sciences, Tampere University, 33250 Tampere, Finland; heini.huhtala@tuni.fi \\ 4 Department of Virology, Medicum, University of Helsinki, 00290 Helsinki, Finland; antti.vaheri@helsinki.fi \\ * Correspondence: johanna.tietavainen@tuni.fi
}

Citation: Tietäväinen, J.; Laine, O.; Mäkelä, S.; Huhtala, H.; Pörsti, I.; Vaheri, A.; Mustonen, J. ABO and Rhesus Blood Groups in Acute Puumala Hantavirus Infection. Viruses 2021, 13, 2271. https:/ / doi.org/10.3390/v13112271

Academic Editor: Helle Bielefeldt-Ohmann

Received: 30 September 2021 Accepted: 10 November 2021 Published: 13 November 2021

Publisher's Note: MDPI stays neutral with regard to jurisdictional claims in published maps and institutional affiliations.

Copyright: (c) 2021 by the authors. Licensee MDPI, Basel, Switzerland. This article is an open access article distributed under the terms and conditions of the Creative Commons Attribution (CC BY) license (https:/ / creativecommons.org/licenses/by/ $4.0 /)$.

\begin{abstract}
Puumala hantavirus (PUUV) causes hemorrhagic fever with renal syndrome. We aimed to evaluate whether $\mathrm{ABO}$ and rhesus blood groups associate with the susceptibility or the severity of PUUV infection. We analyzed blood groups in 289 adult patients treated in Tampere University hospital due to PUUV infection during the years 1982-2017. Patients' blood group distribution was compared to that of healthy, voluntary blood donors living in the Tampere University Hospital responsibility area $(n=21,833)$. The severity of PUUV infection, as judged by the severity of acute kidney injury (AKI), thrombocytopenia, inflammation, capillary leakage, and the length of hospital care, was analyzed across the groups. The $\mathrm{ABO}$ and rhesus blood group distributions did not differ between the patients and blood donors. Patients with non-O blood groups had lower systolic blood pressure compared to patients with blood group $\mathrm{O}$, but there was no difference in other markers of capillary leakage or in the severity of AKI. Minor deviations in the number of platelets and leukocytes were detected between the $\mathrm{O}$ and non-O blood groups. To conclude, patients with blood group $\mathrm{O}$ may be less susceptible to hypotension, but otherwise blood groups have no major influences on disease susceptibility or severity during acute PUUV infection.
\end{abstract}

Keywords: Puumala hantavirus; ABO blood groups; rhesus blood groups; capillary leakage; AKI; blood pressure

\section{Introduction}

Puumala hantavirus (PUUV) is a zoonotic pathogen that causes a febrile illness called hemorrhagic fever with renal syndrome (HFRS) in humans. PUUV is a member of Orthohantavirus genus in the Hantaviridae family, order Bunyavirales, and it is the sole human pathogenetic hantavirus in Finland. There are 1000-2500 reported cases annually in Finland with a seroprevalence of $12.5 \%$ in the adult population [1,2]. Humans are infected by the vaporized excreta of the bank vole (Myodes glareolus) that is the virus's reservoir. The high season of infection ranges from October to January. The number of infections peaks at 3-4 year intervals tightly following the fluctuation in the number of bank voles [1].

The clinical picture of HFRS includes high fever, acute kidney injury (AKI), thrombocytopenia and increased capillary leakage. Although most cases are mild, the infectioninduced capillary leakage can cause a circulatory shock, and about $6 \%$ of the hospitalized patients need transient dialysis treatment $[1,3]$. Bleeding diathesis is rare and case fatality in Finland is less than $0.1 \%$ [4]. Host genetic factors influence the clinical course of the disease [5].

The distribution of ABO blood groups differs geographically. A selection pressure caused by infections, the strongest driving force being malaria, has been offered as a possible explanation. In endemic malaria areas, blood group $\mathrm{O}$ dominates, and its' prevalence 
may reach $90 \%$ [6-8]. Severe malaria is caused by the intracellular Plasmodium falciparum parasite. Infected erythrocytes bind to uninfected erythrocytes forming so called rosettes that may occlude microvascular blood flow and contribute to the development of severe malaria [9]. The rosette formation is reduced in blood group $\mathrm{O}$ red cells, thus offering a pathophysiological explanation to the survival benefit provided by blood group O. In dengue fever, severe disease is more common in patients with blood group $A B$, whereas blood group $\mathrm{O}$ is significantly under-represented in the severe hemorrhagic form of dengue fever [10-12]. During the 2003 severe acute respiratory syndrome coronavirus (SARS-CoV) outbreak, individuals with blood group $\mathrm{O}$ were also less likely to be infected after being exposed to the virus [13], and the same appears to be true in the ongoing SARS-CoV-2 pandemic [14-17]. In contrast, individuals with blood group A are more prone to SARS-CoV2infection [14-17]. However, considerable discrepancy exists whether ABO blood groups affect disease severity. Blood group B individuals have lower risk of hepatitis B (HBV) infection, while blood group $\mathrm{O}$ associates with increased risk of norovirus infection $[18,19]$. Therefore, possible survival advantage provided by different blood groups varies depending on the infective agent and, in many infections, such as in HIV, the relationship with infection and $\mathrm{ABO}$ and rhesus blood groups remains controversial or inconclusive [20]. In addition to infections, an association between cancer, cardiovascular diseases, and thrombosis with $\mathrm{ABO}$ blood groups, has been detected [21].

Although HFRS caused by PUUV is often a mild disease, PUUV and COVID-19 infections share similar features including AKI, capillary leakage, and a cytokine storm. In the current study we aimed to evaluate whether the susceptibility of PUUV infection, and the severity of the disease, is influenced by $\mathrm{ABO}$ and rhesus blood groups.

\section{Materials and Methods}

\subsection{Subjects}

The initial study cohort included 569 adult patients treated in Tampere University Hospital, Finland, due to serologically confirmed acute PUUV infection during the years 19822017. The information about $\mathrm{ABO}$ and rhesus blood groups were collected retrospectively and was available from 289 (51\%) patients. All patients were ethnic Finns (Caucasian).

A detailed medical history of the patients was obtained, and all patients were carefully clinically examined. Blood pressure, heart rate and weight were measured at least daily during hospital care.

Out of the 289 patients, $30(10 \%)$ had one or several previous diagnoses: hypertension $(n=12)$, hyperlipidemia $(n=4)$, type 2 diabetes $(n=4)$, hypothyroidism $(4)$, coronary heart disease $(n=3)$, coeliac disease $(n=2)$, idiopathic thrombocytopenia (2), bronchial asthma (2) and psoriasis $(n=2)$. Two patients were pregnant, and one was breastfeeding. None of the patients had a known chronic kidney disease before the PUUV infection.

The information about the $\mathrm{ABO}$ and rhesus blood group distribution in Finland and in the Pirkanmaa district around Tampere University Hospital, Finland, was obtained from the Finnish Red Cross Blood Service. The information included 157,223 first blood donations in Finland, including 21,833 blood donations in Pirkanmaa district, during the years 2000-2010 (Ph.D., Hannele Sareneva, Finnish Red Cross, personal communication), Table 1.

All patients provided a written informed consent, and the study with its' extensions was approved by the Ethics Committee of the Tampere University Hospital (study codes 96161, 97166, 99256, R04180, R15007 and R09206). 
Table 1. ABO and rhesus blood group distribution in patients with Puumala hantavirus (PUUV) infection and in blood donors in the Pirkanmaa district, Finland.

\begin{tabular}{|c|c|c|c|c|}
\hline & \multicolumn{2}{|c|}{$\begin{array}{c}\text { Patients } \\
n=289\end{array}$} & \multicolumn{2}{|c|}{$\begin{array}{c}\text { Blood Donors in Pirkanmaa } \\
\qquad n=21,833\end{array}$} \\
\hline & Number & $\%$ & Number & $\%$ \\
\hline A & 126 & 43.6 & 8989 & 41.2 \\
\hline B & 48 & 16.6 & 3733 & 17.1 \\
\hline $\mathrm{AB}$ & 22 & 7.6 & 1741 & 8.0 \\
\hline $\mathrm{O}$ & 93 & 32.2 & 7370 & 33.8 \\
\hline $\mathrm{Rh}+$ & 249 & 86.2 & 19002 & 87.0 \\
\hline $\mathrm{Rh}-$ & 40 & 13.8 & 2831 & 13.0 \\
\hline
\end{tabular}

\subsection{Laboratory Determinations}

The diagnosis of PUUV infection was made by detecting the typical granular staining pattern of acute infection and/or low avidity of IgG antibodies in immunofluorescence using PUUV -infected Vero E6 cells as antigens, and/or by detecting PUUV IgM antibodies by an "in-house" enzyme-linked immunosorbent assay based on baculovirus-expressed PUUV nucleocapsid protein. The development and the use of the above and diagnostic methods have been described elsewhere [22].

Plasma creatinine was analyzed by Vitros (Johnson and Johnson, Rochester, NY, USA) until the year 1999 and by Cobas Integra (F. Hoffmann-La Roche Ltd., Basel, Switzerland) from thereafter. Blood cell count was determined by automated hematological cell counters (Bayer Diagnostics, Elkhart, IN, USA) and albumin concentrations using routine automated chemistry analyzers. All laboratory determinations were performed by the Laboratory Centre of the Pirkanmaa Hospital District (later named Fimlab laboratories), Tampere, Finland.

Laboratory analysis from 289 study subjects were available as follows: plasma creatinine 287 (99\%), C-reactive protein (CRP) 267 (92\%), blood count including hematocrit 276 (96\%), leukocytes $278(96 \%)$, platelets $279(97 \%)$, plasma albumin $112(39 \%)$ and ALT in $94 / 289$ (33\%). Information about body mass index (BMI) was available from 140 patients (48\%). Shock was defined as systolic blood pressure under $90 \mathrm{mmHg}$ and clinical symptoms of a shock such as pale, cold, or clammy skin, rapid breathing, and tachycardia. The information of shock was available from 195 patients (67\%). Blood pressure at arrival to the hospital and the minimum blood pressure during hospital care were available from 173 $(60 \%)$ and $268(93 \%)$ patients, respectively. In the analysis of laboratory variables, minimum or maximum values were used in the statistical analysis as indicated in Tables 2-5.

Table 2. Clinical findings in 289 patients with PUUV infection according to ABO blood group.

\begin{tabular}{|c|c|c|c|c|c|c|c|c|c|}
\hline & \multicolumn{2}{|l|}{$\begin{array}{c}\mathrm{A} \\
n=126\end{array}$} & \multicolumn{2}{|l|}{$\begin{array}{c}\text { B } \\
n=48\end{array}$} & \multicolumn{2}{|l|}{$\begin{array}{c}\mathrm{AB} \\
n=22\end{array}$} & \multicolumn{2}{|c|}{$\begin{array}{c}\mathrm{O} \\
n=93\end{array}$} & \multirow[t]{2}{*}{$p$ Value } \\
\hline & Median/Number & Range/\% & Median/Number & Range/\% & Median/Number & Range/\% & Median/Number & Range/\% & \\
\hline Age (years) & 38.9 & $20.4-68.9$ & 35.3 & $19.7-61.2$ & 35.4 & $21.0-58.2$ & 41.4 & $21.5-65.7$ & 0.257 \\
\hline Male/female & $89 / 37$ & $71 / 29$ & $35 / 13$ & $73 / 27$ & $12 / 10$ & $55 / 45$ & $66 / 27$ & $71 / 29$ & $0.440^{+}$ \\
\hline BMI & 24.7 & $17.5-35.4$ & 22.0 & $18.9-35.8$ & 25.3 & $18.6-37.6$ & 24.7 & $20.6-44.2$ & 0.092 \\
\hline Shock $\tau$ & $7 / 87$ & 8.0 & $3 / 35$ & 8.6 & $0 / 15$ & 0 & $0 / 58$ & 0 & $0.078^{*}$ \\
\hline $\begin{array}{c}\text { Systolic BP } \\
\text { initial (mmHg) }\end{array}$ & 125 & $60-180$ & 120 & $90-158$ & 131 & $105-168$ & 135 & $100-174$ & 0.010 \\
\hline $\begin{array}{l}\text { Diastolic BP } \\
\text { initial (mmHg) }\end{array}$ & 80 & $30-110$ & 75 & 0-95 & 85 & $60-100$ & 80 & $60-112$ & 0.167 \\
\hline $\begin{array}{l}\text { Min systolic BP } \\
(\mathrm{mmHg})\end{array}$ & 120 & $60-160$ & 110 & $80-180$ & 120 & $90-160$ & 120 & $74-155$ & 0.036 \\
\hline $\begin{array}{l}\text { Min diastolic } \\
\mathrm{BP}(\mathrm{mmHg})\end{array}$ & 72 & 36-100 & 70 & 40-109 & 75 & $60-90$ & 70 & 50-90 & 0.482 \\
\hline
\end{tabular}


Table 2. Cont

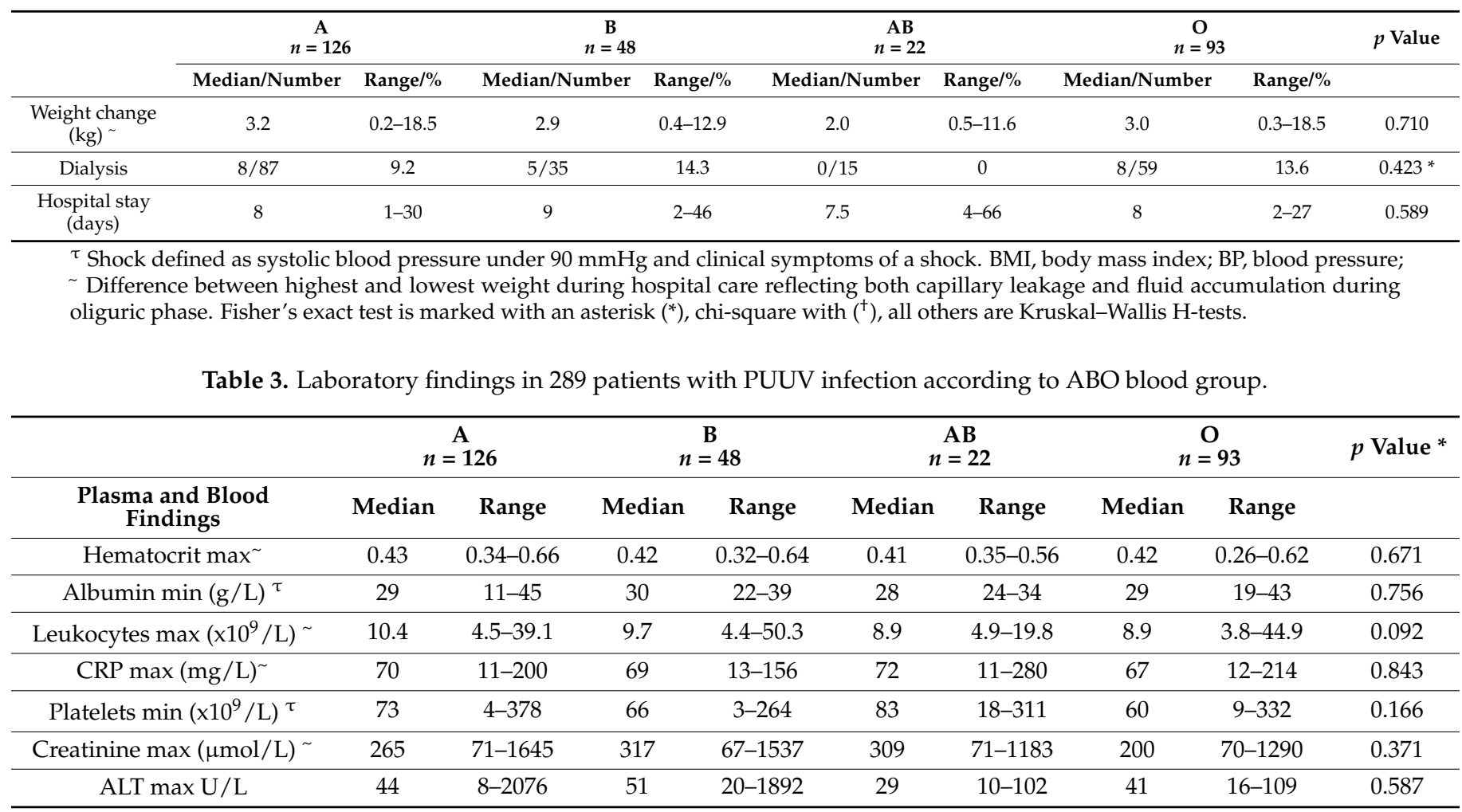

${ }^{*}$ Kruskal-Wallis H-tests; maximum value during hospitalization; ${ }^{\tau}$ minimum value during hospitalization; CRP, C-reactive protein; ALT, alanine aminotransferase.

Table 4. Clinical findings in 289 patients with PUUV infection in non-O (A, B and AB) blood group against $\mathrm{O}$ blood group.

\begin{tabular}{cccccc}
\hline & \multicolumn{2}{c}{$\begin{array}{c}\text { Non-O (A, B, AB) } \\
n=196\end{array}$} & \multicolumn{2}{c}{$\begin{array}{c}\text { O } \\
n=93\end{array}$} & Value \\
\cline { 2 - 6 } & Median/Number & Range/\% & Median/Number & Range/\% & \\
\hline Age (years) & 38.6 & $19.7-68.9$ & 41.4 & $21.5-65.7$ & 0.088 \\
\hline Male/female & $136 / 60$ & $69 / 31$ & $66 / 27$ & $71 / 29$ & $0.891^{\dagger}$ \\
\hline BMI & 24.3 & $17.5-37.6$ & 24.7 & $20.6-44.24$ & 0.218 \\
\hline Shock ${ }^{\tau}$ & $10 / 137$ & 7.3 & $0 / 58$ & 0 & $0.035^{*}$ \\
\hline $\begin{array}{c}\text { Systolic BP initial } \\
\text { (mmHg) }\end{array}$ & 125 & $60-180$ & 135 & $100-174$ & 0.006 \\
\hline $\begin{array}{c}\text { Diastolic BP } \\
\text { initial (mmHg) }\end{array}$ & 80 & $30-110$ & 80 & $60-112$ & 0.173 \\
\hline $\begin{array}{c}\text { Min systolic BP } \\
\text { (mmHg) }\end{array}$ & 119 & $60-180$ & 120 & $74-155$ & 0.063 \\
\hline $\begin{array}{c}\text { Min diastolic BP } \\
\text { (mmHg) }\end{array}$ & 70 & $36-109$ & 70 & $50-90$ & 0.786 \\
\hline $\begin{array}{c}\text { Weight change } \\
\text { (kg) }\end{array}$ & 3 & $0.2-18.5$ & 3 & $0.3-18.5$ & 0.550 \\
\hline $\begin{array}{c}\text { Dialysis } \\
\text { Hospital stay } \\
\text { (days) }\end{array}$ & $13 / 137$ & 9.5 & $8 / 59$ & 13.6 & $0.452^{\dagger}$ \\
\hline
\end{tabular}

${ }^{\tau}$ Shock defined as systolic blood pressure under $90 \mathrm{mmHg}$ and clinical symptoms of a shock. BMI, body mass index; BP, blood pressure; Difference between highest and lowest weight during hospital care reflecting both capillary leakage and fluid accumulation during oliguric phase. Fisher's exact test is marked with an asterisk $\left(^{*}\right)$ chi-square with $\left({ }^{+}\right)$, all others are Kruskal-Wallis H-tests. 
Table 5. Laboratory findings in 289 patients with PUUV infection in non-O (A, B and AB) blood group against $\mathrm{O}$ blood group.

\begin{tabular}{|c|c|c|c|c|c|}
\hline \multirow[b]{2}{*}{$\begin{array}{l}\text { Plasma and Blood } \\
\text { Findings }\end{array}$} & \multicolumn{2}{|c|}{$\begin{array}{c}\text { Non-O }(\mathrm{A}, \mathrm{B}, \mathrm{AB}) \\
n=196\end{array}$} & \multicolumn{2}{|c|}{$\begin{array}{c}O \\
n=93\end{array}$} & \multirow[t]{2}{*}{$p$ Value * } \\
\hline & Median & Range & Median & Range & \\
\hline Hematocrit max & 0.42 & $0.32-0.66$ & 0.42 & $0.26-0.62$ & 0.830 \\
\hline Albumin $\min (\mathrm{g} / \mathrm{L})^{\tau}$ & 29 & $11-45$ & 29 & $19-43$ & 0.726 \\
\hline Leukocytes $\max \left(\times 10^{9} / \mathrm{L}\right) \sim$ & 10.1 & $4.4-50.3$ & 8.9 & $3.8-44.7$ & 0.047 \\
\hline $\mathrm{CRP} \max (\mathrm{mg} / \mathrm{L}) \sim$ & 70 & $11-280$ & 67 & $12-214$ & 0.459 \\
\hline Platelets $\min \left(\times 10^{9} / \mathrm{L}\right)^{\tau}$ & 71 & $3-378$ & 60 & $9-332$ & 0.041 \\
\hline Creatinine $\max (\mu \mathrm{mol} / \mathrm{L}) \sim$ & 278 & $67-1645$ & 200 & 70-1290 & 0.086 \\
\hline ALT max U/L & 44 & 8-2076 & 41 & 16-109 & 0.832 \\
\hline
\end{tabular}

${ }^{*}$ Kruskal-Wallis H-tests; ${ }^{~ m a x i m u m ~ v a l u e ~ d u r i n g ~ h o s p i t a l i z a t i o n ; ~}{ }^{\tau}$ minimum value during hospitalization; CRP, C-reactive protein; ALT, alanine aminotransferase.

\subsection{Statistical Analysis}

The data are presented as medians and ranges for continuous variables and numbers and percentages for categorical variables. Groups were compared using the Kruskal-Wallis test or Mann-Whitney U test, as appropriate. Bonferroni correction for multiple comparisons was applied in the post hoc analyses. The chi-square or Fisher's exact tests were used to examine differences in proportions, as appropriate. The differences between group means for the initial and minimum blood pressure were calculated with $95 \%$ confidence intervals. All analyses were performed using IBM SPSS Statistics version 25 (IBM, Armonk, NY, USA).

\section{Results}

\section{Clinical and Laboratory}

There was no difference in the distribution of $\mathrm{ABO}$ or rhesus blood groups between the hospitalized patients with PUUV infection and blood donors in Pirkanmaa district around Tampere University Hospital ( $p=0.872$ for $\mathrm{ABO}$ and $p=0.660$ for rhesus blood groups) Table 1. A similar result was obtained when the blood group distribution of patients was compared with blood donors in Finland ( $p=0.834$ for ABO and $p=0.932$ for rhesus blood groups).

For disease severity analysis, patients were grouped according to the $\mathrm{ABO}$ and rhesus blood groups in three different ways. First, we compared A, B, AB, and O blood groups separately (Tables 2 and 3). Second, we compared $O$ versus non-O (A, B, and AB combined) blood groups (Tables 4 and 5 ). The third grouping comprised a comparison of rhesus positive and negative patients. Different aspects of HFRS including AKI (maximum creatinine), thrombocytopenia (minimum platelet count), inflammation (maximum CRP and leukocyte count) and capillary leakage (weight change, blood pressure upon arrival and minimum blood pressure, signs of clinical shock as well as minimum albumin concentration and maximum hematocrit) were analyzed across the groups.

The clinical characteristics and laboratory findings according to $\mathrm{A}, \mathrm{B}, \mathrm{AB}$, and $\mathrm{O}$ blood groups are presented in Tables 2 and 3. The initial systolic blood pressure upon arrival to the hospital as well as the minimum blood pressure detected during hospital treatment differed significantly between the groups. In pairwise comparisons with the Bonferroni correction, only blood groups $\mathrm{B}$ and $\mathrm{O}$ differed significantly for initial and minimum systolic blood pressure. Patients with blood group O had $12.9 \mathrm{mmHg}$ (CI 4.5-21.3 mmHg; $p=0.003)$ higher initial blood pressure and $7.6 \mathrm{mmHg}(\mathrm{CI} 1.7-13.7 \mathrm{mmHg} ; p=0.011)$ higher minimum systolic blood pressure compared to blood group $\mathrm{B}$.

The effect of $\mathrm{ABO}$ blood group on initial blood pressure was similar in both sexes. When grouped according to tertiles or quartiles of age, the effect of blood group $\mathrm{O}$ on blood pressure was similar in all age groups (data not shown). Also, when the patients were 
divided into two groups according to BMI, the effect of blood group on blood pressure remained similar (data not shown).

There were no statistically significant differences in the variables reflecting disease severity namely maximum hematocrit or minimum albumin level (capillary leakage), maximum leukocyte count or CRP (inflammation), minimum platelet count or in maximum plasma creatinine concentration (AKI), between the ABO blood groups, Table 3.

When blood group $\mathrm{O}$ was compared with non-O blood groups (Table 4), patients with non-O blood group had lower initial systolic blood pressure and they were more often in clinical shock. The initial systolic blood pressure was $8.6 \mathrm{mmHg}$ (95\% CI 2.4-14.7 mmHg; $p=0.006$ ) higher in patients with blood group $\mathrm{O}$ compared to non-O blood groups.

Patients with blood group $\mathrm{O}$ had slightly lower leukocyte count when compared with non-O blood groups, but there was no difference in maximum CRP level (Table 5). Blood group $\mathrm{O}$ was associated with lower minimum platelet count.

Altogether 13/289 (4.5\%) patients had the diagnosis of hypertension and/or medication affecting blood pressure due to some other illness such as the coronary heart disease. The results remained essentially the same when these patients were excluded from the analysis (data not shown).

In addition, we compared patients expressing antigen $\mathrm{A}$ ( $\mathrm{A}$ and $\mathrm{AB}$ combined), $\mathrm{B}$ or $\mathrm{O}$, or expressing antigen $\mathrm{B}$ ( $\mathrm{B}$ and $\mathrm{AB}$ combined), $\mathrm{A}$ or $\mathrm{O}$. The groups again differed significantly in terms of initial and minimum systolic blood pressure. After Bonferroni correction, the only statistically significant differences were detected between blood groups $\mathrm{O}$ vs. $\mathrm{B}$ and blood groups $\mathrm{O}$ vs. $\mathrm{B}$ and $\mathrm{AB}$ combined. No differences in laboratory parameters were found between the groups.

There were no differences either in the clinical or in the laboratory variables when grouped according to the rhesus factor (data not shown).

\section{Discussion}

We have shown here that $\mathrm{ABO}$ and rhesus blood groups do not associate with susceptibility to PUUV infection in Finland. Hospitalized patients with non-O blood groups appear to have lower systolic blood pressure during PUUV infection compared to patients with blood group $\mathrm{O}$. In pairwise analysis, the only significant difference in blood pressure was detected between blood groups $\mathrm{O}$ and $\mathrm{B}$. Patients with blood group $\mathrm{O}$ have also less severe leukocytosis without a difference in CRP value, but more severe thrombocytopenia when compared with patients with non-O blood groups. To the best of our knowledge, this is the first time the association of blood groups and hantaviral infections has been investigated.

$\mathrm{ABO}$ blood groups have a role beyond transfusion medicine and are considered a part of the innate immune system [21]. The $\mathrm{ABO}$ histo-blood groups consist of $\mathrm{A}$ and $\mathrm{B}$ antigens that are co-dominant products of a single $\mathrm{ABO}$ gene, and an $\mathrm{H}$ antigen, that is a result of homozygous inheritance of two null $\mathrm{ABO}$ alleles. The system creates four blood types (A, $\mathrm{B}, \mathrm{AB}$ and $\mathrm{O}$ ) [23]. Group $\mathrm{O}$ individuals express the $\mathrm{H}$ antigen, which is the biosynthetic precursor of the $\mathrm{A}$ and $\mathrm{B}$ antigens. In addition to red cells, $\mathrm{ABH}$ antigens are expressed in the endothelium, platelets, intestinal mucosa, kidney, heart, gastrointestinal tract, female reproductive organs, as well as in fluids and secretions including saliva, mucus, and plasma. However, the level of $\mathrm{ABH}$ expression both in cells and in secretions between individuals of the same blood type varies greatly, depending on the other histo-blood group antigens, namely secretor status and the expression of Lewis antigen [23].

The expression of $\mathrm{ABH}$ antigens in different oligosaccharide backbones influences the recognition of antigens by antibodies and by microbes. As microbes often use glycosylated cell-surface receptors for their attachment and entry into cells, it is conceivable that $\mathrm{ABH}$ antigens may play a role in determining susceptibility to infections [21,23]. Accordingly, histo-blood group antigens function as a receptor or attachment factors on gut epithelial surfaces. Children with blood groups $\mathrm{A}$ and $\mathrm{AB}$ are more prone to rotavirus gastroenteritis compared to children with blood group $\mathrm{O}$. The resistance of infection is also dependent 
on the secretor and Lewis antigen status as well as the rotavirus genotype, which varies geographically [24].

In the current study, no differences in the susceptibility of PUUV infection in relation to either $\mathrm{ABO}$ or rhesus blood groups were detected. As the study participants consist solely of hospitalized patients with a relatively severe disease, the detection of a clinically significant association is possible even in a relatively small sample size. Accordingly, other genetic factors such as the HLA B8-DR3 phenotype, have been shown to be more prevalent and to associate with a more severe disease in hospitalized patients with PUUV infection [25].

In SARS-CoV-2 infection a relation between ABO blood groups and infection susceptibility has been found with lower susceptibility in subjects with blood group $\mathrm{O}$. The body produces natural antibodies against those ABO blood group antigens that are not expressed in the own cells [23]. In SARS-CoV-2, the titer and types of natural antibodies (IgM vs. IgG), spatial hindrance of viral attachment to its receptor by the bound antibodies, and destruction of the antibody coated viruses by the complement, have been presented as explanations for the lower incidence of infection in blood group O individuals [26-30]. Moreover, rhesus-positive individuals have been suggested to be more prone to severe SARS-CoV-2 disease [31].

In the present study, patients with non-O blood groups, especially those with blood group $B$, had lower systolic blood pressure compared to blood group $O$. In two recent studies an association with blood group $\mathrm{O}$ and hypertension was observed [32,33]. In our study, only 12/289 (4\%) patients had a diagnosis of hypertension before hospital treatment and there was no statistically significant difference in hypertension prevalence between blood groups (data not shown). Whether the differences in blood pressure detected during PUUV infection represent a true susceptibility to hypotension in patients with non-O blood groups or is more related to the higher likelihood of hypertension in blood group $\mathrm{O}$ patients needs further evaluation. As other markers of capillary leakage, namely the level of maximum hematocrit, minimum plasma albumin concentration, or change of weight during hospital treatment, did not differ in the blood groups, increased capillary leakage is not a likely explanation for the observed difference in blood pressure.

No clinically significant difference in blood cell counts in relation to ABO blood groups has been detected in large population-based studies [32]. However, during PUUV infection, minimum platelet count and maximum leukocyte count were lower in patients with blood group $\mathrm{O}$ when compared with the other blood groups. The reason for this is currently unknown.

Platelet activation and thrombus formation result from the complex interplay between the vascular endothelium, plasma proteins and platelets. Increased platelet consumption on the injured endothelium is considered to be the mechanism of thrombocytopenia in hantavirus infections, and the level of several markers of platelet activation and aggregation are altered during PUUV infection [1,34]. Fibrinogen and von Willebrand factor (VWF) are upregulated in the acute phase, whereas the levels of a disintegrin and metalloproteinase with thrombospondin type 1 domain 13 (ADAMTS13) activity and fibronectin are downregulated. Fibrinogen level also negatively correlates with thrombocytopenia [35]. The function of VWF is to mediate platelet activation and aggregation to the injured endothelium. It is currently not known whether the results above differ in relation to blood groups during infection. However, in a steady state, 20-25\% lower level of VWF and factor VIII are detected in the serum of blood group $\mathrm{O}$ individuals $[23,36]$. In contrast, blood group $\mathrm{O}$ carriers exhibit higher concentrations of endothelium-derived soluble adhesion molecules (P-selectin, E-selectin and soluble intercellular adhesion molecule-1 (sICAM-1)), while $\mathrm{ABH}$ antigenicity is even expressed on the platelet endothelial cell adhesion molecule-1 (PECAM-1) [36]. The circulating level of soluble P-selectin, as well as soluble glycoprotein VI, are also influenced by acute PUUV infection [37].

ABO glycosyltransferases modify platelet surface glycoproteins (GP), glycolipids and glycosphingolipids, many of which participate in platelet activation and thrombosis via 
different mechanisms $[21,23,36]$. It is possible that $\mathrm{ABO}$ modifications result in changes of platelet function. Of these, GP IIb/IIIa complex mediates platelet activation and aggregation via the binding of fibrinogen, fibronectin and VWF. Interestingly, GP IIIA-also named $\beta 3$ integrin-is a receptor for hantaviruses. In addition to platelets, it is expressed on endothelial cells and macrophages. Hantaviruses bind quiescent platelets preventing their activation and direct them to adhere to the endothelial cells via $\beta 3$ integrins [34]. Accordingly, platelets from PUUV-infected patients show impaired aggregation to stimuli other than collagen [38].

In PUUV infection, neutrophils are activated by PUUV-infected endothelial cells, and the activation is more likely to occur indirectly via virus-infected microvascular endothelial cells rather than directly through virus contacts with neutrophils [39]. Neutrophil activation leads to the release of neutrophil extracellular traps (NETs) and/or release of antimicrobial proteins (degranulation). As an indication of NETosis in PUUV infection, histones and cell free DNA (cfDNA) are detected in plasma [39-41]. In addition, it is currently appreciated that platelets are crucial in neutrophil activation and NET production [42]. Therefore, platelet and leukocyte number and function are interrelated with $\mathrm{ABO}$ blood groups in a multitude of ways, which may explain the observed differences in the number of platelets and leukocytes in this study.

The association of $\mathrm{ABO}$ blood groups with different diseases has a been a subject of investigation and debate for decades. It appears that a true connection is evident but the pathophysiological mechanisms as well as the extent of the effects in different diseases vary. Although the investigations concerning $\mathrm{ABO}$ blood groups have dominated, a connection between secretor status, Lewis antigen as well as rhesus (Rh) blood group with diseases has also been made [23].

\section{Conclusions}

According to our results, $\mathrm{ABO}$ and rhesus blood groups do not influence the susceptibility to PUUV infection. Patients with non-O blood group may be more prone to hypotension and the number of platelets and leukocytes during PUUV infection may be affected by $\mathrm{ABO}$ blood groups.

Supplementary Materials: The following are available online at https:/ /www.mdpi.com/article/10.3 390/v13112271/s1, The original data are available as Supplementary Materials.

Author Contributions: Conceptualization, J.T. and J.M.; methodology, J.T. and J.M.; software, J.T.; validation, J.T., J.M. and H.H.; formal analysis, J.T. and H.H.; investigation, J.T., J.M. and S.M.; resources, J.M., A.V., I.P.; data curation, J.T.; writing —original draft preparation, J.T.; writing—review and editing, J.T., J.M., O.L., I.P., S.M., A.V. and H.H.; supervision, J.M. and A.V.; project administration, J.T.; funding acquisition, J.M. and A.V. All authors have read and agreed to the published version of the manuscript.

Funding: This study was supported by the Competitive State Research Financing of the Expert Responsibility Area of Tampere University Hospital under grant numbers 9X033, 9V040 (JM) and 9V025 (OL), Sigrid Jusélius Foundation under grant number MS568 (AV and JM), Tampere Tuberculosis Foundation under grant number MS759 (JM), and Magnus Ehrnrooth Foundation (AV).

Institutional Review Board Statement: The study with its' extensions was conducted according to the guidelines of the Declaration of Helsinki, and approved by the Ethics Committee of the Tampere University Hospital (study codes 96131, 97166, 99256, R04180, R15007 and R09206).

Informed Consent Statement: Informed consent was obtained from all subjects involved in the study.

Data Availability Statement: Original data are available as Supplementary Materials.

Acknowledgments: The skillful assistance of Katriina Ylinikkilä and Eini Eskola is greatly appreciated. The authors are thankful for the kind collaboration of Tomi Koski and Hannele Sareneva.

Conflicts of Interest: The authors declare no conflict of interest. The funders had no role in the design of the study, in the collection, analyses, or interpretation of data; in the writing of the manuscript, or in the decision to publish the results. 


\section{References}

1. Vaheri, A.; Strandin, T.; Hepojoki, J.; Sironen, T.; Henttonen, H.; Mäkelä, S.; Mustonen, J. Uncovering the Mysteries of Hantavirus Infections. Nat. Rev. Microbiol. 2013, 11, 539-550. [CrossRef]

2. Latronico, F.; Mäki, S.; Rissanen, H.; Ollgren, J.; Lyytikäinen, O.; Vapalahti, O.; Sane, J. Population-Based Seroprevalence of Puumala Hantavirus in Finland: Smoking as a Risk Factor. Epidemiol. Infect. 2018, 146, 367-371. [CrossRef]

3. Mustonen, J.; Outinen, T.; Laine, O.; Pörsti, I.; Vaheri, A.; Mäkelä, S. Kidney Disease in Puumala Hantavirus Infection. Infect. Dis. 2017, 49, 321-332. [CrossRef] [PubMed]

4. Mustonen, J.; Mäkelä, S.; Outinen, T.; Laine, O.; Jylhävä, J.; Arstila, P.T.; Hurme, M.; Vaheri, A. The Pathogenesis of Nephropathia Epidemica: New Knowledge and Unanswered Questions. Antiviral Res. 2013, 100, 589-604. [CrossRef] [PubMed]

5. Mustonen, J.; Partanen, J.; Kanerva, M.; Pietilä, K.; Vapalahti, O.; Pasternack, A.; Vaheri, A. Genetic Susceptibility to Severe Course of Nephropathia Epidemica Caused by Puumala Hantavirus. Kidney Int. 1996, 49, 217-221. [CrossRef] [PubMed]

6. Degarege, A.; Gebrezgi, M.T.; Ibanez, G.; Wahlgren, M.; Madhivanan, P. Effect of the ABO Blood Group on Susceptibility to Severe Malaria: A Systematic Review and Meta-Analysis. Blood Rev. 2019, 33, 53-62. [CrossRef]

7. Panda, A.K.; Panda, S.K.; Sahu, A.N.; Tripathy, R.; Ravindran, B.; Das, B.K. Association of ABO Blood Group with Severe Falciparum Malaria in Adults: Case Control Study and Meta-Analysis. Malaria J. 2011, 10, 309. [CrossRef] [PubMed]

8. Cserti, C.M.; Dzik, W.H. The ABO Blood Group System and Plasmodium Falciparum Malaria. Blood 2007, 110, 2250-2258. [CrossRef]

9. Rowe, A.J.; Handel, I.G.; Mahamadou, T.A.; Deans, A.; Lyke, K.E.; Koné, A.; Diallo, D.A.; Raza, A.; Kai, O.; Marsh, K.; et al. Blood Group O Protects Against Severe Plasmodium Falciparum Malaria through the Mechanism of Reduced Rosetting. Proc. Natl. Acad. Sci. USA 2007, 104, 17471-17476. [CrossRef] [PubMed]

10. Murugananthan, K.; Subramaniyam, S.; Kumanan, T.; Owens, L.; Ketheesan, N.; Noordeen, F. Blood Group AB is Associated with Severe Forms of Dengue Virus Infection. Virus Dis. 2018, 29, 103-105. [CrossRef]

11. Ravichandran, S.; Ramya, S.R.; Kanungo, R. Association of ABO Blood Groups with Dengue Fever and its Complications in a Tertiary Care Hospital. J. Lab Physicians 2019, 11, 265-269. [CrossRef]

12. Kalayanarooj, S.; Gibbons, R.V.; Vaughn, D.; Green, S.; Nisalak, A.; Jarman, R.G.; Mammen, M.P.; Perng, G. Blood Group AB is Associated with Increased Risk for Severe Dengue Disease in Secondary Infections. J. Infect. Dis. 2007, 195, 1014-1017. [CrossRef] [PubMed]

13. Cheng, Y.; Cheng, Y.; Cheng, G.; Chui, C.H.; Lau, F.Y.; Chan, P.K.S.; Ng, M.H.L.; Sung, J.J.Y.; Wong, R.S.M. ABO Blood Group and Susceptibility to Severe Acute Respiratory Syndrome. JAMA 2005, 293, 1447-1451.

14. Golinelli, D.; Boetto, E.; Maietti, E.; Maria, P.F. The Association between ABO Blood Group and SARS-CoV-2 Infection: A MetaAnalysis. PLoS ONE 2020, 15, e0239508. [CrossRef] [PubMed]

15. Leaf, R.K.; Al-Samkari, H.; Brenner, S.K.; Gupta, S.; Leaf, D.E. ABO Phenotype and Death in Critically Ill Patients with COVID-19. Br. J. Haematol. 2020, 190, e204-e208. [CrossRef]

16. Liu, N.; Zhang, T.; Ma, L.; Zhang, H.; Wang, H.; Wei, W.; Pei, H.; Li, H. The Impact of ABO Blood Group on COVID-19 Infection Risk and Mortality: A Systematic Review and Meta-Analysis. Blood Rev. 2020, 48, 100785. [CrossRef]

17. Wu, B.; Gu, D.; Yu, J.; Yang, J.; Shen, W. Association between ABO Blood Groups and COVID-19 Infection, Severity and Demise: A Systematic Review and Meta-Analysis. Infect. Genet Evol. 2020, 84, 104485. [CrossRef] [PubMed]

18. Jing, W.; Zhao, S.; Liu, J.; Liu, M. ABO Blood Groups and Hepatitis B Virus Infection: A Systematic Review and Meta-Analysis. BMJ Open 2020, 10, e034114. [CrossRef]

19. Liao, Y.; Xue, L.; Gao, J.; Wu, A.; Kou, X. ABO Blood Group-Associated Susceptibility to Norovirus Infection: A Systematic Review and Meta-Analysis. Infect. Genet Evol. 2020, 81, 104245. [CrossRef] [PubMed]

20. Davison, G.M.; Hendrickse, H.L.; Matsha, T.E. Do Blood Group Antigens and the Red Cell Membrane Influence Human Immunodeficiency Virus Infection? Cells 2020, 9, 845. [CrossRef] [PubMed]

21. Franchini, M.; Bonfanti, C. Evolutionary Aspects of ABO Blood Group in Humans. Clin. Chim. Acta 2015, 444, 66-71. [CrossRef]

22. Vaheri, A.; Vapalahti, O.; Plyusnin, A. How to Diagnose Hantavirus Infections and Detect them in Rodents and Insectivores. Rev. Med. Virol. 2008, 18, 277-288. [CrossRef] [PubMed]

23. Cooling, L. Blood Groups in Infection and Host Susceptibility. Clin. Microbiol. Rev. 2015, 28, 801-870. [CrossRef]

24. Pérez-Ortín, R.; Vila-Vicent, S.; Carmona-Vicente, N.; Santiso-Bellón, C.; Rodríguez-Díaz, J.; Buesa, J. Histo-blood group antigens in children with symptomatic rotavirus infection. Viruses 2019, 11, 339. [CrossRef] [PubMed]

25. Mäkelä, S.; Mustonen, J.; Ala-Houhala, I.; Hurme, M.; Partanen, J.; Vapalahti, O.; Vaheri, A.; Pasternack, A. Human Leukocyte Antigen-B8-DR3 is a More Important Risk Factor for Severe Puumala Hantavirus Infection than the Tumor Necrosis Factor-A(-308) G/A Polymorphism. J. Infect. Dis. 2002, 186, 843-846. [CrossRef]

26. Focosi, D. Anti-A Isohaemagglutinin Titres and SARS-CoV-2 Neutralization: Implications for Children and Convalescent Plasma Selection. Br. J. Haematol. 2020, 190, e148-e150. [CrossRef]

27. Gérard, C.; Maggipinto, G.; Minon, J. COVID-19 and ABO Blood Group: Another Viewpoint. Br. J. Haematol. 2020, 190, e93-e94. [CrossRef]

28. Li, J.; Wang, X.; Chen, J.; Cai, Y.; Deng, A.; Yang, M. Association between ABO Blood Groups and Risk of SARS-CoV-2 Pneumonia. Br. J. Haematol. 2020, 190, 24-27. [CrossRef] 
29. Deleers, M.; Breiman, A.; Daubie, V.; Maggetto, C.; Barreau, I.; Besse, T.; Clémenceau, B.; Ruvoën-Clouet, N.; Fils, J.; Maillart, E.; et al. Covid-19 and Blood Groups: ABO Antibody Levels may also Matter. Int. J. Infect. Dis. 2021, 104, 242-249. [CrossRef] [PubMed]

30. Zaidi, F.Z.; Zaidi, A.R.Z.; Abdullah, S.M.; Zaidi, S.Z.A. COVID-19 and the ABO Blood Group Connection. Transfus. Apher. Sci. 2020, 59, 102838. [CrossRef]

31. Taha, S.A.H.; Osman, M.E.M.; Abdoelkarim, E.A.A.; Holie, M.A.I.; Elbasheir, M.M.; Abuzeid, N.M.K.; Al-Thobaiti, S.; Fadul, S.B.; Konozy, E.H.E. Individuals with a Rh-Positive but Not Rh-Negative Blood Group are More Vulnerable to SARS-CoV-2 Infection: Demographics and Trend Study on COVID-19 Cases in Sudan. New Microbes New Infect. 2020, 38, 100763. [CrossRef] [PubMed]

32. Groot, H.E.; Villegas Sierra, L.E.; Said, M.A.; Lipsic, E.; Karper, J.C.; van der Harst, P. Genetically Determined ABO Blood Group and its Associations with Health and Disease. Arterioscler. Thromb. Vasc. Biol. 2020, 40, 830-838. [CrossRef]

33. Li, S.; Schooling, C.M. A Phenome-Wide Association Study of ABO Blood Groups. BMC Med. 2020, 18, 334. [CrossRef] [PubMed]

34. Gavrilovskaya, I.N.; Gorbunova, E.E.; Mackow, E.R. Pathogenic Hantaviruses Direct the Adherence of Quiescent Platelets to Infected Endothelial Cells. J. Virol. 2010, 84, 4832-4839. [CrossRef]

35. Laine, O.; Mäkelä, S.; Mustonen, J.; Helminen, M.; Vaheri, A.; Lassila, R.; Joutsi-Korhonen, L. Platelet Ligands and ADAMTS13 during Puumala Hantavirus Infection and Associated Thrombocytopenia. Blood Coagul. Fibrinol. 2011, 22, 468-472. [CrossRef] [PubMed]

36. Zhong, M.; Zhang, H.; Reilly, J.P.; Chrisitie, J.D.; Ishihara, M.; Kumagai, T.; Azadi, P.; Reilly, M.P. ABO Blood Group as a Model for Platelet Glycan Modification in Arterial Thrombosis. Arterioscler. Thromb. Vasc. Biol. 2015, 35, 1570-1578. [CrossRef]

37. Connolly-Andersen, A.; Sundberg, E.; Ahlm, C.; Hultdin, J.; Baudin, M.; Larsson, J.; Dunne, E.; Kenny, D.; Lindahl, T.L.; Ramström, S.; et al. Increased Thrombopoiesis and Platelet Activation in Hantavirus-Infected Patients. J. Infect. Dis. 2015, 212, 1061-1069. [CrossRef] [PubMed]

38. Laine, O.; Joutsi-Korhonen, L.; Lassila, R.; Koski, T.; Huhtala, H.; Vaheri, A.; Mäkelä, S.; Mustonen, J. Hantavirus Infection-Induced Thrombocytopenia Triggers Increased Production but Associates with Impaired Aggregation of Platelets Except for Collagen. Thromb. Res. 2015, 136, 1126-1132. [CrossRef]

39. Strandin, T.; Mäkelä, S.; Mustonen, J.; Vaheri, A. Neutrophil Activation in Acute Hemorrhagic Fever with Renal Syndrome is Mediated by Hantavirus-Infected Microvascular Endothelial Cells. Front. Immunol. 2018, 9, 2098. [CrossRef] [PubMed]

40. Outinen, T.K.; Kuparinen, T.; Jylhävä, J.; Leppänen, S.; Mustonen, J.; Mäkelä, S.; Pörsti, I.; Syrjänen, J.; Vaheri, A.; Hurme, M. Plasma Cell-Free DNA Levels are Elevated in Acute Puumala Hantavirus Infection. PLoS ONE 2012, 7, e31455. [CrossRef]

41. Raftery, M.J.; Lalwani, P.; Krautkrämer, E.; Peters, T.; Scharffetter-Kochanek, K.; Krüger, R.; Hofmann, J.ö.; Seeger, K.; Krüger, D.H.; Schönrich, G. B2 Integrin Mediates Hantavirus-Induced Release of Neutrophil Extracellular Traps. J. Exp. Med. 2014, 211, 1485-1497. [CrossRef] [PubMed]

42. Kim, S.; Jenne, C.N. Role of Platelets in Neutrophil Extracellular Trap (NET) Production and Tissue Injury. Semin. Immunol. 2016, 28, 546-554. [CrossRef] [PubMed] 